\title{
Prognostic Potential of Serum VEGF Expression in Breast Cancer: A Study from Egypt
}

MOHAMED GABER ${ }^{1}$, HYTHAM FAYED², MAHER BADR ${ }^{3}$, AMIRA IBRAHIM FAYAD $^{4}$

\section{ABSTRACT}

Introduction: Basal Vascular Endothelial Growth Factor (VEGF) levels are elevated in the serum of Breast Cancer (BC) patients. Positive correlation has been reported between VEGF expression and microvessel density in primary $\mathrm{BC}$ sections. The relapse-free survival rate of patients with VEGF-poor tumours was significantly higher than that of VEGF-rich tumours, suggesting that expression of VEGF may be associated with poor BC prognosis.

Aim: To evaluate the role of VEGF as a prognostic factor in breast cancer patients.

Materials and Methods: This case-control study was conducted on BC patients admitted to the Oncology Unit or the Outpatient Clinics, Main Alexandria University Hospitals, Faculty of Medicine, Egypt. Clinically diagnosed 75 BC patients were divided into Group IA: 45 patients diagnosed with early BC Stage I and II; and Group IB: 30 patients diagnosed with advanced BC Stage III and IV. Apparently, healthy 60 females (relatives/companions) were recruited as the control group (Group II). Serum VEGF levels were measured by Enzyme-linked immunosorbent assay (ELISA). Serum VEGF data were expressed as median (min- max). Qualitative data were analysed using Chi-square test and Fisher's-Exact test or Monte Carlo correction. Quantitative data were analysed using Mann Whitney ( $Z$ ) test and Kruskal Wallis $(H)$ tests. Spearman's coefficient $\left(r_{s}\right)$ was performed to determine correlation of serum VEGF with age, tumour size and grade. Binary logistic regression was done to predict the probability of several clinical parameters with respect to the VEGF measurement. Significance level was set at $5 \%$.

Results: The median VEGF serum levels showed significant difference between the three studied groups $(p<0.001)$. Serum VEGF was significantly increased in both Groups IA/IB patients compared to healthy controls $(p<0.001)$; and were significantly higher in advanced than early BC patients $(p<0.001)$. Serum VEGF was significantly associated with tumour size, tumour grade, Oestrogen Receptor (ER), Progesterone Receptor (PR), luminal tumour, and triple negative BC. BC cases who developed metastasis expressed significantly higher serum VEGF (Group IA: $p \leq 0.001$; Group IB: $p=0.024$ ).

Conclusion: Serum VEGF may serve as an independent prognostic biomarker in $\mathrm{BC}$ patients that merits prospective validation.

\section{INTRODUCTION}

Breast Cancer (BC) is the highest recorded cancer amongst women, affecting over 2 million women each year. Globally, it is the second most common type of cancer that comprises $30 \%$ of all new cancer cases among women in the US [1].

Hanahan D and Weinberg RA, postulated the six initial 'Hallmarks of Cancer' that establish the molecular and cellular basis of cancer [2]. Induction of angiogenesis is one of these crucial hallmarks for tumour development. In-depth studies on angiogenesis are required to progressively interpret the current knowledge underlying cancer growth, detection and treatment.

Proper risk stratification of BC patients is an important strategy in monitoring tumour progression and improving tumour treatment outcome and survival. It helps in prioritising stratification strategies based on awareness of staging markers that promotes a proper choice of an adequate treatment protocol. Treatment of choice for $\mathrm{BC}$ that is positive for progesterone and oestrogen receptors (PR+ and $\mathrm{ER+}$ ) is hormonal therapy. However, de novo failure to respond to this treatment strategy or acquired resistance following primary response to treatment remains a clinical challenge. Failure of treatment may be the consequence of an improper risk stratification of cancer patients or lack of understanding of the cross-talk between key players of tumour pathogenesis including sex hormones and growth factors [3]. Hence, elucidation of these factors can ensure improvement of treatment strategies.
Currently, the key prognostic biomarkers in early-stage BC are tumour size, grade, Lymph Node (LN) status, ER, PR and Human Epidermal Growth Factor Receptor- (HER2) status [4-6]. These markers are used mainly to identify patients who are eligible for hormonal therapy or/and adjuvant chemotherapy. Nevertheless, further studies are required to identify diagnostic, prognostic or predictive biomarkers to improve the therapeutic outcome.

Scientific evidence reports an angiogenic-dependent nature of BC, where angiogenesis plays an important role in cancer growth and metastasis [7,8]. Expression of angiogenic factors by BC cells has been vastly studied at the molecular (mRNA) or functional (protein) level in both node-negative and positive breast cancers [9-11]. These findings rationalise the need for advanced studies on angiogenic growth factors to identify possible targets for antiangiogenic therapy, for eliminating resistant tumour cells that cannot be defeated by anti-hormone treatment $[12,13]$.

In recent times the key regulators of angiogenesis are VEGF and basic Fibroblast growth factor (bFGF), which have received much attention [14-16]. VEGF and its isoforms are potent regulators of the angiogenesis signalling pathway that provide nutrients and oxygen required for tumour growth $[12,17,18]$. Clinical studies have shown that $\mathrm{BC}$ patients expressing increased VEGF levels failed to respond to hormone therapy or suffered early recurrence, indicating that VEGF may be responsible for anti-hormone resistance $[19,20]$.

Majority of the published research work reports the tissue expression 
of VEGF by Immunohistochemistry (IHC) [9,21]. However, the assessing of circulating soluble serum biomarker as VEGF would be of considerable benefits. Clinical implementation of serum VEGF biomarker analysis in $\mathrm{BC}$ work-up will be cost effective, rapid and reliable test over more subjective approaches as $\mathrm{IHC}$ that entails arduous procedures.

Therefore, the present study was designed to evaluate the serum VEGF levels and its' role at time of initial diagnosis of BC and after 6 months following treatment as a potential prognostic factor in different $B C$ intrinsic subtypes and stages. The inclusions of serum VEGF measurement in the initial tumour work-up will help to risk stratify BC patients and identify patients at high risk of developing metastasis or relapse.

\section{MATERIALS AND METHODS}

The present case-control study was conducted from January 2016 to January 2017. Ethics Committee approval was obtained from the Faculty of Medicine Alexandria University (approval no: 0103645). All the procedures followed were in accordance with Helsinki Declaration, 1964 and its later amendments. BC patients admitted to the Oncology Unit or visiting the Outpatient Clinics, Main Alexandria University hospitals, Faculty of Medicine, Alexandria, Egypt were recruited. Purpose and procedure of the study was explained to all the participants, and informed consent was obtained before commencement of the study.

During this one year study, a total of 1500 specimens were received at the Histopathology Department for examination. Amongst them, 75 (95\% Cl, 80\% statistical power) cases positive for BC by histopathological analysis were selected for the study. Based on the diagnosis, the samples were divided into; Group IA: 45 patients diagnosed with early BC stage I and II, mean age 44.67 \pm 11.09 years; Group IB: 30 patients diagnosed with advanced BC stage III and IV mean age 55.27 \pm 11.67 years. Apparently, healthy 60 females (relatives/companions) were recruited as the control group (Group II), mean age $40.67 \pm 11.9$ years.

\section{Inclusion Criteria}

BC patients have histologically proven positive, adequate venous blood samples available for evaluation, normal cardiac imaging and no other diagnosed malignancies were included.

\section{Exclusion Criteria}

Patients diagnosed with liver, renal (laboratory) or heart failure (cardiac imaging) or patients with chronic inflammatory diseases including autoimmune diseases (patient's history) or viral infection (laboratory); HBV, HCV, and HIV were excluded. Patients suffered from uncontrolled DM ( $\mathrm{HbA} 1 \mathrm{C})$ or uncontrolled hypertension (medical history and follow-up) were also excluded.

For all the BC patients, a thorough family and clinical history were taken. Clinical examination for tumour size, LN examination, and routine laboratory investigations were carried out. Radiological examination for BC diagnosis included Ultrasonography (USG) and mammography for both breasts. For detection of metastasis, chest X-ray, abdominal and pelvis USG, CT for chest, abdomen, pelvis, brain (when indicated), and bone scanning were done.

\section{Histopathological Examination}

The excised tumour tissues and LN (s) were examined histopathologically, where the tumour tissue sections were diagnosed and clinicopathological parameters such as age, histological type, size, tumour grade, lymphatic or vascular invasion, LN metastasis, ER, PR, and HER2 status were recorded for each case [Table/Fig-1].

Quantification of VEGF at Diagnosis and after Treatment Serum samples were collected from all the study subjects at the time of diagnosis (before any surgical intervention or starting any
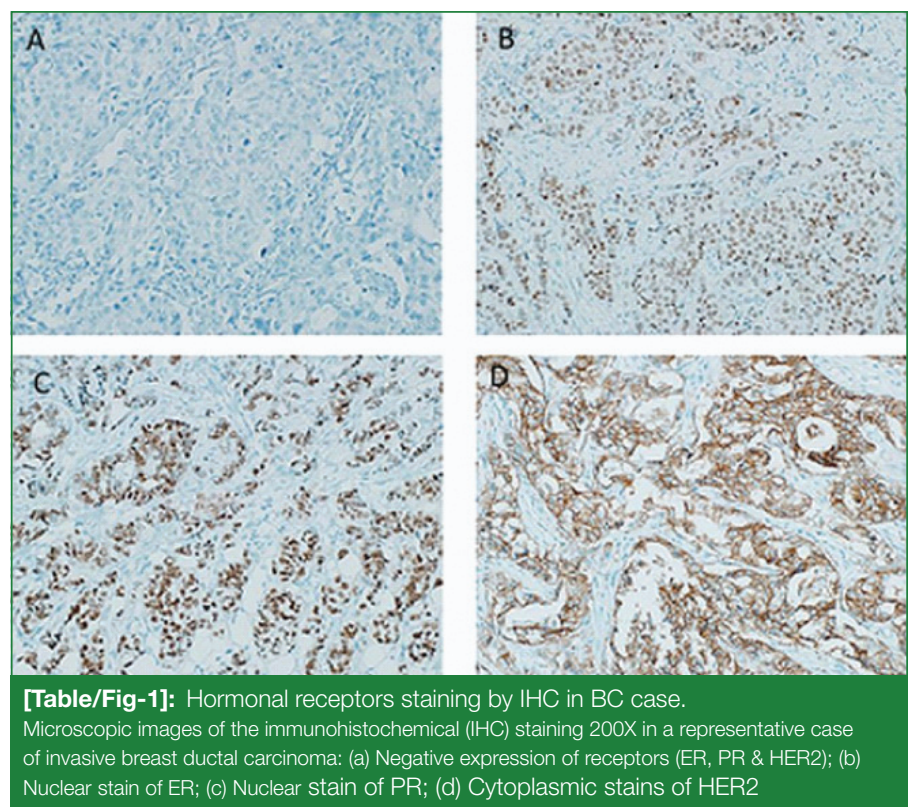

treatment protocols) and after 6 months of treatment. Sera were obtained by centrifugation and samples were stored at $-80^{\circ} \mathrm{C}$ until the analysis of VEGF levels. Serum VEGF levels were measured by using the double antibody sandwich ELISA (Human VEGF PicoKine ELISA Kit, USA; Catalog No. EK0539) according to the manufacturers' instructions. Optical density absorbance was read at $450 \mathrm{~nm}$ and human VEGF concentration of the samples was calculated from the standard curve. Serum VEGF reference range was taken to be $31.2 \mathrm{pg} / \mathrm{mL}-2000 \mathrm{pg} / \mathrm{mL}$.

\section{STATISTICAL ANALYSIS}

Data were analysed using IBM's Statistical Package for the Social Sciences (SPSS) software, Version 20.0. (Armonk, NY: IBM Corp) $[22,23]$. Parametric quantitative data were expressed using mean, Standard Deviation (SD) and median. Significance level was set at $5 \%$. Qualitative data were analysed using Chi-square test and Fisher'sExact test or Monte Carlo correction for Chi-square when more than $20 \%$ of the cells have expected count less than 5. F-test (ANOVA) was used to compare normally distributed quantitative variables and Post-Hoc test (LSD) for pairwise comparisons. Mann-Whitney (S) test and Kruskal Wallis $(\mathrm{H})$ test were used for comparing abnormally distributed quantitative variables between the studied groups.

Spearman Coefficient ( $\rho$ ) was used to correlate between two distributed abnormally quantitative variables. Binary logistic regression was done to predict the probability of a certain nominal variable, given the VEGF measurement.

\section{RESULTS}

Clinical data for the studied BC cases (Group IA and IB) including tumour size, grade, histopathological examination and BC intrinsic subtypes are presented in [Table/Fig-2].

Analysis of median VEGF serum levels showed significant difference between the three studied groups $(p<0.001)$ [Table/Fig-3]. The median VEGF serum level was significantly increased in Group IB than Group IA (Median=583 (160-940.4) and 290.4 (59.8-650) IU/ $\mathrm{mL}$, respectively). In the controls, the median VEGF serum level was 61.7 (35-96.7) IU/mL. Serum VEGF was significantly increased in both Group IA and Group IB patients, compared to healthy controls $(p<0.001$ for each), and was significantly increased in advanced (Group IB) than early (Group IA) BC patients $(p<0.001)$.

Association between serum VEGF and different clinic-pathological parameters are presented in [Table/Fig-4]. Median serum VEGF levels showed significantly higher values as the tumour size increased $(p=0.017)$ and the tumour grade advanced $(p=0.008)$. Serum VEGF levels in ER or PR negative tumours showed significantly higher values than positive tumours ( $p=0.013,0.012$, respectively). 
Studying the relation of serum VEGF levels with intrinsic subtypes showed that VEGF serum levels were significantly lower in luminal tumour subtypes $(p=0.013)$, while significantly higher in triple negative subtype $(p=0.005)$.

\begin{tabular}{|c|c|c|c|c|}
\hline & $\begin{array}{c}\text { Group IA } \\
\text { (early) }\end{array}$ & $\begin{array}{c}\text { Group IB } \\
\text { (advanced) }\end{array}$ & \multirow{2}{*}{$\begin{array}{l}\text { Test of signifi- } \\
\text { cance }\end{array}$} & \multirow[t]{2}{*}{$p$} \\
\hline & $\mathrm{n}=45(\%)$ & $\mathrm{n}=30(\%)$ & & \\
\hline \multicolumn{5}{|l|}{ Tumour size } \\
\hline $\mathrm{T} 1$ & 12 (26.7\%) & $0(0.0 \%)$ & $\chi^{2}=3.273$ & $M C p<0.001$ \\
\hline T2 & $33(73.3 \%)$ & 20 (66.7\%) & & \\
\hline T3 & $0(0.0 \%)$ & $8(26.7 \%)$ & & \\
\hline T4 & $0(0.0 \%)$ & 2 (6.7\%) & & \\
\hline \multicolumn{5}{|l|}{ Tumour grade } \\
\hline 1 & $6(13.3 \%)$ & $0(0.0 \%)$ & $\chi^{2}=2.292$ & $\mathrm{MCp}=0.057$ \\
\hline$\|$ & 33 (73.3\%) & 22 (73.3\%) & & \\
\hline III & $6(13.3 \%)$ & 8 (26.7\%) & & \\
\hline Lymph nodes & $30(66.7 \%)$ & $30(100.0 \%)$ & $\chi^{2}=6.000^{*}$ & FEp $\leq 0.001^{*}$ \\
\hline $\begin{array}{l}\text { Lympho-vascular } \\
\text { Invasion }\end{array}$ & $21(46.7 \%)$ & 22 (73.3\%) & $\chi^{2}=5.233$ & $0.022^{\star}$ \\
\hline ER & 36 (80.0\%) & 20 (66.7\%) & $\chi^{2}=1.692$ & $\mathrm{FE} p=0.279$ \\
\hline PR & 33 (73.3\%) & 20 (66.7\%) & $\chi^{2}=0.386$ & $\mathrm{FEp}=0.609$ \\
\hline HER2 & 15 (33.3\%) & 8 (26.7\%) & $\chi^{2}=0.376$ & 0.540 \\
\hline Luminal tumour & 36 (80.0\%) & 20 (66.7\%) & $\chi^{2}=1.692$ & $\mathrm{FEp}=0.279$ \\
\hline HER2-enriched & $6(13.3 \%)$ & 4 (13.3\%) & $\chi^{2}=0.0$ & $\mathrm{FEp}=1.000$ \\
\hline Triple negative & $3(6.7 \%)$ & $6(20.0 \%)$ & $\chi^{2}=3.030$ & $\mathrm{FEp}=0.144$ \\
\hline \multicolumn{5}{|c|}{$\begin{array}{l}\text { [Table/Fig-2]: Clinical data for the studied breast cancer cases (group IA/B). } \\
\text { ER: Estrogen receptor; PR: progesterone receptor; HER2: human epidermal growth factor receptor } \\
\text { 2; } \chi^{2} \text { : Chi-square test, MC: Monte Carlo test; FE: Fisher's-Exact test; p: Significance of the factors in } \\
\text { the model; *: Statistically significant at } p \leq 0.05\end{array}$} \\
\hline
\end{tabular}



\begin{tabular}{|c|c|c|c|c|c|}
\hline \multicolumn{6}{|c|}{ Group IA $\square$ Group IB $\square$ Grous } \\
\hline $\begin{array}{l}\text { Serum VEGF } \\
\mathrm{IU} / \mathrm{mL}\end{array}$ & $\begin{array}{c}\text { Group IA early } \\
(n=45)\end{array}$ & $\begin{array}{l}\text { Group IB } \\
\text { advanced } \\
(\mathrm{n}=30)\end{array}$ & $\begin{array}{l}\text { Group II } \\
\text { control } \\
(\mathrm{n}=60)\end{array}$ & $\mathrm{H}$ & $p$ \\
\hline Min-Max & 59.8-650 & $160-940.4$ & $35-\mathrm{c}$ & \multirow{3}{*}{$27.861^{*}$} & \multirow{3}{*}{$<0.001^{*}$} \\
\hline lean \pm SD & $286.35 \pm 144$ & $544.3 \pm 247$ & $62.76 \pm 18$ & & \\
\hline ledian & 290.4 & 583 & 61.7 & & \\
\hline Sig. bet. grps & \multicolumn{3}{|c|}{$p 1<0.001^{\star}, p 2<0.001^{\star}, p 3<0.001^{*}$} & & \\
\hline \multicolumn{6}{|c|}{$\begin{array}{l}\text { [Table/Fig-3]: Comparison between the three studied groups according to serum } \\
\text { VEGF (IU/mL). } \\
\text { Horisontal bars representing the comparison between serum VEGF levels in each group present- } \\
\text { ed as Median (min-max) and SD. } \text {. }^{* *}: p<0.001 \text { (Table below shows the figure data in numerical } \\
\text { values); H: Kruskal wallis test Sig. bet. grps: significance between groups; } p^{1}: \text { v value for Mann } \\
\text { Whittney test for comparing between group IA and group IB; } p^{2}: p \text { value for Mann Whitney test } \\
\text { for comparing between group IA and group II; } p^{3}: p \text { value for Mann Whitney test for comparing } \\
\text { between group IB and group II; *: Statistically significant at } p \leq 0.05\end{array}$} \\
\hline
\end{tabular}

[Table/Fig-5] shows the correlation between serum VEGF with age, tumour size and tumour grade. The present data showed positive significant correlation between VEGF and both tumour size ( $\rho=0507$; $\mathrm{p}=0.004)$ and tumour grade $\left(r_{s}=0.573 ; p=0.001\right)$, where median serum VEGF significantly increased as tumour size increased or tumour grade advanced.

\begin{tabular}{|c|c|c|c|c|}
\hline & No of cases & $\begin{array}{l}\text { Serum VEGF (IU/mL) } \\
\text { median (min-max) }\end{array}$ & Test of significance & $p$ \\
\hline \multicolumn{5}{|c|}{ Tumour size } \\
\hline $\mathrm{T} 1$ & 12 & $282.40(89.20-649.60)$ & $\mathrm{H}=11.364^{*}$ & $0.017^{\star}$ \\
\hline T2 & 53 & $296.0(59.80-787.0)$ & & \\
\hline Т3 & 8 & $675(601.0-805.0)$ & & \\
\hline T4 & 2 & 845.2 (750.0-940.40) & & \\
\hline \multicolumn{2}{|c|}{ Sig. bet. group } & \multicolumn{2}{|c|}{$\mathrm{p} 1=0.882, \mathrm{p} 2=0.043^{\star}, \mathrm{p} 3=0.005^{\star}$} & \\
\hline \multicolumn{5}{|c|}{ Tumour grade } \\
\hline 1 & 6 & $114.30(59.80-168.80)$ & $\mathrm{H}=9.615^{\star}$ & $0.008^{*}$ \\
\hline ॥ & 55 & $293.20(82.60-787.0)$ & & \\
\hline III & 14 & $583.20(376.40-940.40)$ & & \\
\hline \multicolumn{2}{|c|}{ Sig. bet. group } & \multicolumn{2}{|c|}{$p 1=0.060, p 2=0.046^{*}, p 3=0.013^{*}$} & \\
\hline \multicolumn{5}{|c|}{ Lymph nodes } \\
\hline$-v e$ & 15 & $290.40(59.80-342.0)$ & $S=1.642$ & 0.101 \\
\hline$+v e$ & 60 & $386.0(82.60-940.40)$ & & \\
\hline \multicolumn{5}{|c|}{ Lympho-vascular Invasion } \\
\hline$-v e$ & 32 & $293.20(59.80-787.0)$ & $S=1.016$ & 0.310 \\
\hline$+v e$ & 43 & $398.70(82.60-940.40)$ & & \\
\hline \multicolumn{5}{|l|}{ ER } \\
\hline$-v e$ & 9 & $558.90(252.80-940.40)$ & $S=2.486^{*}$ & $0.013^{*}$ \\
\hline$+v e$ & 56 & $289.30(59.80-787.0)$ & & \\
\hline \multicolumn{5}{|l|}{ PR } \\
\hline$-v e$ & 22 & $516.80(252.80-940.40)$ & $S=2.512^{*}$ & $0.012^{\star}$ \\
\hline$+v e$ & 53 & $288.20(59.80-787.0)$ & & \\
\hline \multicolumn{5}{|c|}{ HER2 } \\
\hline$-v e$ & 52 & $296.0(82.60-940.40)$ & $S=0.272$ & 0.786 \\
\hline$+v e$ & 23 & $386.0(59.80-787.0)$ & & \\
\hline \multicolumn{5}{|c|}{ Luminal tumour } \\
\hline No & 9 & $558.90(252.80-940.40)$ & $S=2.486^{\star}$ & $0.013^{*}$ \\
\hline Yes & 56 & $289.30(59.80-787.0)$ & & \\
\hline \multicolumn{5}{|c|}{ HER2-enriched } \\
\hline No & 65 & $311.50(59.80-940.40)$ & $S=0.427$ & 0.669 \\
\hline Yes & 10 & $398.70(252.80-516.80)$ & & \\
\hline \multicolumn{5}{|c|}{ Triple negative } \\
\hline No & 66 & $293.20(59.80-787.0)$ & $\mathrm{S}=2.807^{\star}$ & $0.005^{\star}$ \\
\hline Yes & 9 & $744.60(601.0-940.40)$ & & \\
\hline
\end{tabular}

[Table/Fig-4]: Association between serum VEGF (IU/mI) with different clinic-pathological parameters.

VEGF: vascular endothelial growth factor; ER: Oestrogen receptor; PR: progesterone receptor, HER2: human epidermal growth factor receptor 2; H: Kruskal Wallis-H test; S: Mann Whitney test, Sig. bet. group: significance between groups; p: Significance of the factors in the model; : Statistically significant at $p \leq 0.05$

\begin{tabular}{|l|c|c|}
\hline \multirow{2}{*}{} & \multicolumn{2}{|c|}{ Serum VEGF (IU/mL) } \\
\cline { 2 - 3 } & $\mathrm{r}_{\mathrm{s}}$ & $\mathrm{p}$ \\
\hline Age (Years) & 0.241 & 0.110 \\
\hline Tumour Size & $0.507^{\star}$ & $0.004^{\star}$ \\
\hline Tumour Grade & $0.573^{\star}$ & $0.001^{*}$ \\
\hline
\end{tabular}

[Table/Fig-5]: Correlation between serum VEGF (IU/mL) with age, tumour size and tumour grade for total sample.

$\rho$ : Spearman coefficient; *: Statistically significant at $p \leq 0.05$

The probability of predicting a specified clinical or histopathological factor, given the serum VEGF, was studied using binary logistic regression test [Table/Fig-6]. The tested factors were age, tumour size, tumour grade, luminal tumour (BC subtype) and tumour staging (early/advanced stage). The only independent factor detected to significantly correlate with serum VEGF was tumour staging 
$(\mathrm{OR}=2.421 ; 95 \% \mathrm{Cl}=11.9-331.0 ; \mathrm{p}=0.047)$. To assess the prognostic potential of measuring serum VEGF biomarker in BC, follow-up of the BC patients (Group IA and Group IB) was done for a period of 6 months [Table/Fig-7]. In both groups, cases who developed metastasis were those patients who expressed significantly higher serum VEGF (for Group IA, $p=<0.001$; for Group IB, $p=0.024$ ).

\begin{tabular}{|c|c|c|c|c|c|c|}
\hline Variables & B & SE & OR & $\mathrm{p}$ & & $\mathrm{Cl}_{\mathrm{UL}}$ \\
\hline Age & -4.051 & 3.194 & -1.269 & 0.217 & -10.643 & 2.540 \\
\hline Tumour size & 96.788 & 67.909 & 1.425 & 0.167 & -43.370 & 236.947 \\
\hline Tumour grade & 171.051 & 89.810 & 1.905 & 0.069 & -14.308 & 356.410 \\
\hline Luminal tumour & -64.931 & 106.347 & -0.611 & 0.547 & -284.419 & 154.558 \\
\hline Tumour stage & 159.571 & 83.073 & $2.421^{\star}$ & $0.047^{\star}$ & 11.884 & 331.026 \\
\hline \multicolumn{7}{|c|}{$\begin{array}{l}\text { [Table/Fig-6]: Binary logistic regression for factors affecting serum VEGF. } \\
\text { B: Un standardised coefficients of the factor in the model; SE: Standard error of the coefficient; } \\
\text { OR: Odd ratio; p: Significance of the factors in the model, *: Statistically significant at p } \leq 0.05 \text {; } \\
\text { 95\% Cl: Confidence interval; LL: Lower limit; UL: Upper limit }\end{array}$} \\
\hline
\end{tabular}

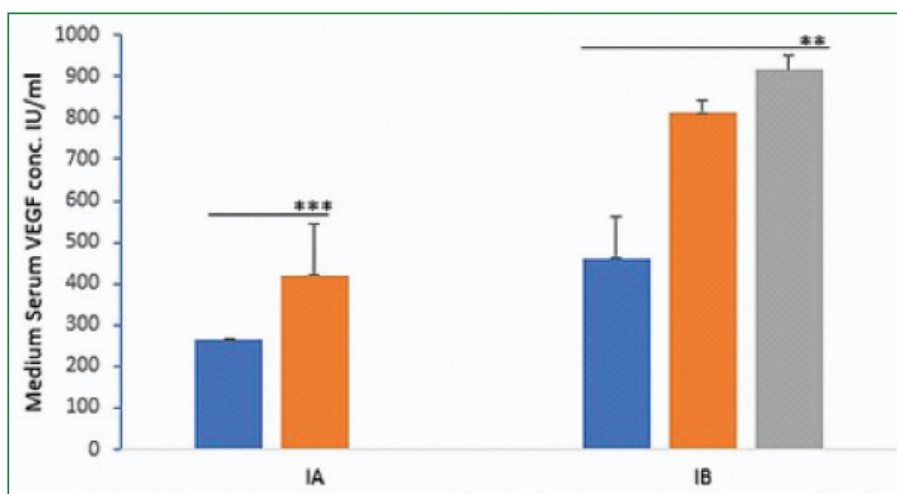

- DFS $=$ Metastasis $=$ Death

\begin{tabular}{|c|c|c|c|c|c|}
\hline & Disease free & Metastasis & Death & H & $p$ \\
\hline Group IA & $(\mathrm{n}=36)$ & $(n=9)$ & $(n=0)$ & \multirow{3}{*}{$36.818^{*}$} & \multirow{3}{*}{$<0.001^{*}$} \\
\hline Early & 266.20 & 421.0 & - & & \\
\hline$(n=45)$ & $(59.8-376.4)$ & (386.0-649.60) & & & \\
\hline Group IB & $(n=24)$ & $(n=4)$ & $(n=2)$ & \multirow{3}{*}{$7.457^{*}$} & \multirow{3}{*}{$0.024^{*}$} \\
\hline Advanced & 461.60 & 813.30 & 915.2 & & \\
\hline$(n=30)$ & (82.6-732.0) & (787.0-839.6) & (890-940.4) & & \\
\hline
\end{tabular}

[Table/Fig-7]: VEGF as prognostic factor evaluated after 6 months of treatment. Histogram showing the prognosis of studied breast cancer patients according to pre-treatment serum VEGF levels; Serum VEGF levels are presented as median (min-max) with SD in each group; ${ }^{* \star}: \mathrm{p}<0.001 ;{ }^{* *}: \mathrm{p}<0.05$ (Table below shows the figure data in numerical values); $\mathrm{H}$ :
Kruskal wallis test $(H) ;{ }^{*}:$ Statistically significant at $\mathrm{p} \leq 0.05$; Serum VEGF are represented as Median (Min-Max)

\section{DISCUSSION}

Targeted therapies in treating cancer have gained more attention in an attempt to hinder tumour progression and metastasis. Inhibition of tumour angiogenesis process is a proposed strategy for cancer treatment, as angiogenesis is an important regulator of cancer growth, invasion and metastasis. The assessment of angiogenesis by evaluation of Intratumoral Microvessel Density (IMD) using immunohistochemistry is a commonly used technique in BC $[9,21]$. Nevertheless, IMD quantification technique is an operator dependent technique making the process variable among laboratories, arduous and requires skills. Hence, identifying serological biomarkers, as a less subjective measurement, that can be used to identify high risk $\mathrm{BC}$ patients can improve clinical and therapeutic management.

In the present study, it was observed that VEGF serum levels were significantly elevated in $\mathrm{BC}$ patients as compared to healthy controls and the levels were significantly much higher in advanced than early BC patients. Therefore, VEGF can be used to identify a subset of breast cancer at higher risk for development of recurrence and distant metastasis. These findings were in accordance with various studies on $\mathrm{BC}$ patients and several other types of cancers where increased VEGF levels were recorded in metastatic than localised tumour stages [9,11,22-25]. Ali EM et al., study also reported significantly increased mean serum VEGF in BC patients preoperatively than postoperatively, when compared to benign breast lesions [21].

Several molecular pathways have been hypothesized to unveil the VEGF's role in BC tumourigenesis. Linderholm BK et al., showed that the combination of increased VEGF expression levels and mutated p53 has been correlated with poor outcome for BC patients. The study suggested that tumour angiogenesis might be conjointly regulated by the increased VEGF and the loss of wild type p53 that functions as tumour suppressor gene [26]. However, some studies reported a relation between BRAC-1 mutation and increased VEGF in $\mathrm{BC}$ patients. Kawai $\mathrm{H}$ et al., study demonstrated that mutated BRCA-1 failed to inhibit VEGF gene transcription activation and protein secretion, mediated through the oestrogen signalling pathway, in a pathogenic mechanism that could promote tumorigenesis and angiogenesis [27]. Hypoxia can induce an increase in the expression of VEGF at molecular (mRNA) and cellular (protein) levels [28]. Bos $R$ et al., investigated the correlation between increased level of the transcriptional factor; Hypoxia inducible factor-1 alpha (HIF-1 $\alpha)$, and VEGF in BC patients [29]. They demonstrated that HIF-1 $\alpha$ expression increased in poorly differentiated and more aggressive BC lesions compared to well-differentiated lesions, and the increased levels of HIF-1 $\alpha$ were significantly associated with increased VEGF [29].

The present study showed positive association between serum VEGF with different clinico-pathological parameters with significantly higher serum VEGF values as the tumour size increased $(p=0.017)$, tumour grade advanced $(p=0.008)$, ER ${ }^{-v e}(p=0.013)$ and $P R^{-v e}$ $(p=0.012)$; while no significant association with HER2 was detected. Additionally, the data showed an increasing trend in serum VEGF with LN involvement or lympho-vascular invasion; however, the differences were not statistically significant. In agreement with the present data, Liu $Y$ et al., reported a positive association of VEGF with tumour size, grade and hormonal receptor in primary invasive BC. However, their study showed positive association with nodal involvement and HER2 expression [22,30]. Goussia A et al., showed positive association of VEGF-A with ER and PR, where high VEGF was detected with negative hormonal receptors. However, their study could not confirm any association with tumour size or LN involvement [31]. In addition, multiple studies could not confirm the association of VEGF with any of the clinico-pathological parameters in invasive BC patients [10,32]. These inconsistent results can be explained in the context of variability of the applied method, as most of the studies were based on IHC staining examination, using different detecting antibodies with different selected cut-offs, in addition to the biological and molecular heterogeneity of studied samples.

Evaluating the relation of serum VEGF levels with BC intrinsic subtypes showed that VEGF serum levels were significantly lower in luminal tumour subtypes $(p=0.013)$, while significantly higher in triple negative subtype ( $p=0.005)$. Similar findings were reported by Linderholm BK et al., where VEGF was significantly higher and had shorter survival time in triple negative BC subtype [33]. Liu $Y$ et al., reported significantly lowered VEGF in luminal A subtype, while VEGF was significantly higher in luminal B subtype and HER2- enriched [22]. Goussia A et al., findings are in partial agreement with the present data, with a positive association between low serum VEGF and luminal subtypes, in contrast to high VEGF in HER2-enriched subtypes [31].

Furthermore, the present study was carried out to establish the probability of predicting a specified clinical or histopathological factor with a known serum VEGF. The only independent factor detected to significantly associated with serum VEGF was tumour staging (early/advanced) $(p=0.032)$, where serum VEGF can be used to predict tumour staging. Follow-up of the BC patients over a 6-month period demonstrated that metastasis occurred in those expressing significantly higher pretreatment serum VEGF. These findings are in accordance with Ali EM et al., who reported that higher VEGF was associated with poor survival rates with significantly lower overall or disease free survival in patients having increased pretreatment VEGF serum levels [21]. 


\section{LIMITATION}

Relatively small sample size. Further studies with larger sample size, and extended treatment time frame for VEGF analysis are required. In addition, correlation study with different treatment protocols could provide more informative data. The present authors also recommend the consideration of setting an optimal cut-off point(s) for serum VEGF that could be correlated to different clinical parameters of BC. Furthermore, the study of the regulation of VEGF gene transcription activation and protein secretion will aid in understanding pathogenic mechanisms that can identify possible targets for novel therapy.

\section{CONCLUSION}

Breast Cancer $(\mathrm{BC})$ is the main cause of death related to cancer among women all over the world which summons the need for the identification of simple, reliable and cost-effective biomarkers particularly in countries with financial constraints. From the present study, it can be concluded that VEGF could serve as an independent prognostic biomarker in $\mathrm{BC}$ patients. BC patients expressing high levels of serum VEGF were associated with advanced tumour grade, presence of distant metastasis and aggressive subtypes. VEGF serum levels maybe used as a predictor of BC staging and can be used to identify $\mathrm{BC}$ patients at high risk of developing metastasis or relapse. Adopting serum VEGF in the routine BC work-up would help in proper selection of BC treatment protocol.

\section{REFERENCES}

[1] Siegel RL, Miller KD, Jemal A. Cancer statistics, 2019. CA Cancer J Clin. 2019;69(1):7-34.

[2] Hanahan D, Weinberg RA. Hallmarks of cancer: the next generation. Cell. 2011;144(5):646-74.

[3] Gutierres MC, Detre S, Johnston S, Mohsin SK, Shou J, Allred DC, et al. Molecular changes in tamoxifen-resistant breast cancer: relationship between estrogen receptor, HER-2, and p38 mitogen-activated protein kinase. J Clin Oncol. 2005;23(11):2469-76.

[4] Esteva FJ, Hortobagyi GN. Prognostic molecular markers in early breast cancer. Breast Cancer Res. 2004;6(3):109-18.

[5] Sheng H, Shong A, Xie S, Wang Y, Sun J, Shang J, et al. Elevated serum HER-2 predicts poor prognosis in breast cancer and is correlated to ADAM10 expression. Cancer Med. 2019;8(2):679-85

[6] Lonning PE. Breast cancer prognostication and prediction: are we making progress? Ann Oncol. 2007;18 Suppl 8:viii3-7.

[7] Dabrosin C. Sex steroid regulation of angiogenesis in breast tissue. Angiogenesis. 2005;8(2):127-36.

[8] Dabrosin C, Margetts PJ, Gauldie J. Estradiol increases extracellular levels of vascular endothelial growth factor in vivo in murine mammary cancer. Int $J$ Cancer. 2003;107(4):535-40.

[9] De Paola F, Granato AM, Scarpi E, Monti F, Medri L, Bianchi S, et al. Vascular endothelial growth factor and prognosis in patients with node-negative breast cancer. Int J Cancer. 2002;98(2):228-33.

[10] Mylona E, Alexandrou P, Giannopoulou I, Liapis G, Sofia M, Keramopoulos A, et al. The prognostic value of vascular endothelial growth factors (VEGFs)-A and -B and their receptor, VEGFR-1, in invasive breast carcinoma. Gynecol Oncol. 2007; 104(3):557-63

[11] Linardou H, Kalogeras KT, Kronenwett R, Kouvatseas G, Wirts RM, Sagouri F, et al. The prognostic and predictive value of mRNA expression of vascular endothelial growth factor family members in breast cancer: a study in primary tumours of high-risk early breast cancer patients participating in a randomised Hellenic Cooperative Oncology Group trial. Breast Cancer Res. 2012;14(6):R145.

[12] Pralhad T, Madhusudan S, Rajendrakumar K. Concept, mechanisms and therapeutics of angiogenesis in cancer and other diseases. J Pharm Pharmacol. 2003;55(8):1045-53.

[13] Carmeliet P, Jain RK. Angiogenesis in cancer and other diseases. Nature. 2000;407(6801):249-57.
[14] Hicklin DJ, Ellis LM. Role of the vascular endothelial growth factor pathway in tumour growth and angiogenesis. J Clin Oncol. 2005;23(5):1011-27.

[15] Faridi A, Rudlowski C, Biesterfeld S, Schuh S, Rath W, Schroder W. Long-term follow-up and prognostic significance of angiogenic basic fibroblast growth factor (bFGF) expression in patients with breast cancer. Pathol Res Pract. 2002;198(1):1-5

[16] Curigliano G, Petit JY, Bertolini F, Colleoni M, Perussotti G, de Braud F, et al. Systemic effects of surgery: quantitative analysis of circulating basic fibroblast growth factor (bFGF), Vascular endothelial growth factor (VEGF) and transforming growth factor beta (TGF-beta) in patients with breast cancer who underwent limited or extended surgery. Breast Cancer Res Treat. 2005;93(1):35-40.

[17] Ferrara N, Gerber HP, LeCouter J. The biology of VEGF and its receptors. Nat Med. 2003;9(6):669-76.

[18] Ferrara N. Vascular endothelial growth factor as a target for anticancer therapy. Oncologist. 2004;9 Suppl 1:2-10.

[19] Manders P, Sweep FC, Tjan-Heijnen VC, Geurts-Moespot A, van Tienoven DT, Foekens JA, et al. Vascular endothelial growth factor independently predicts the efficacy of postoperative radiotherapy in node-negative breast cancer patients. Clin Cancer Res. 2003;9(17):6363-70

20] Foekens JA, Peters HA Grebenchtchikov N, Look MP, Meijer-van Gelder ME, Geurts-Moespot A, et al. High tumour levels of vascular endothelial growth factor predict poor response to systemic therapy in advanced breast cancer. Cancer Res. 2001:61(14):5407-14.

[21] Ali EM, Sheta M, Mohsen. Elevated serum and tissue VEGF associated with poor outcome in breast cancer patients. Alexandria Journal of Medicine. 2011;47(3):217-24.

[22] Liu Y, Tamimi RM, Collins LC, Schnitt SJ, Gilmore HL, Connolly JL, et al. The association between vascular endothelial growth factor expression in invasive breast cancer and survival varies with intrinsic subtypes and use of adjuvant systemic therapy: results from the Nurses' Health Study. Breast Cancer Res Treat. 2011;129(1):175-84.

[23] Ryden L, Jirstrom K, Haglund M, Stal O, Ferno M. Epidermal growth factor receptor and vascular endothelial growth factor receptor 2 are specific biomarkers in triple-negative breast cancer. Results from a controlled randomised trial with long-term follow-up. Breast Cancer Res Treat. 2010;120(2):491-98.

[24] Wang K, Peng HL, Li LK. Prognostic value of vascular endothelial growth factor expression in patients with prostate cancer: a systematic review with metaanalysis. Asian Pac J Cancer Prev. 2012;13(11):5665-69.

[25] Tang RF, Wang SX, Peng L, Wang SX, Shang M, Li SF, et al. Expression of vascular endothelial growth factors $\mathrm{A}$ and $\mathrm{C}$ in human pancreatic cancer. World J Gastroenterol. 2006;12(2):280-86.

[26] Linderholm BK, Lindahl T, Holmberg L, Klaar S, Lennerstrand J, Henriksson R, et al. The expression of vascular endothelial growth factor correlates with mutant p53 and poor prognosis in human breast cancer. Cancer Res. 2001;61(5):2256-60.

[27] Kawai H, Li H, Chun P, Avraham S, Avraham HK. Direct interaction between BRCA1 and the estrogen receptor regulates vascular endothelial growth factor (VEGF) transcription and secretion in breast cancer cells. Oncogene. 2002;21(50):7730-39.

[28] Huang J, Wang Y, Wang L, Pan Y, Chen T. MicroRNA-16 inhibits hypoxiainduced vascular endothelial growth factor expression in ARPE-19 cells. Cutan Ocul Toxicol. 2018;37(3):228-32.

29] Bos R, Shong H, Hanrahan CF, Mommers EC, Semensa GL, Pinedo HM, et al. Levels of hypoxia-inducible factor-1 alpha during breast carcinogenesis. J Nat Cancer Inst. 2001;93(4):309-14

[30] Linderholm B, Bergqvist J, Hellborg H, Johansson U, Linderholm M, von Schoults $\mathrm{E}$, et al. Shorter survival-times following adjuvant endocrine therapy in oestrogenand progesterone-receptor positive breast cancer overexpressing HER2 and/or with an increased expression of vascular endothelial growth factor. Med Oncol. 2009;26(4):480-90.

[31] Goussia A, Simou N, Sagouri F, Manousou K, Lasaridis G, Gogas H, et al. Associations of angiogenesis-related proteins with specific prognostic factors, breast cancer subtypes and survival outcome in early-stage breast cancer patients. A Hellenic Cooperative Oncology Group (HeCOG) trial. PLoS One. 2018;13(7):e0200302.

[32] Haghi AR, Vahedi A, Shekarchi AA, Kamran A. Correlation of serum intercellular adhesion molecule 1 and vascular endothelial growth factor with tumour grading and staging in breast cancer patients. J Cancer Res Ther. 2017:13(2):257-61.

[33] Linderholm BK, Hellborg H, Johansson U, Elmberger G, Skoog L, Lehtio J, et al. Significantly higher levels of vascular endothelial growth factor (VEGF) and shorter survival times for patients with primary operable triple-negative breast cancer. Ann Oncol. 2009;20(10):1639-46.

\section{PARTICULARS OF CONTRIBUTORS:}

1. Professor, Department of Surgery Oncology, Faculty of Medicine, Alexandria University, Alexandria, Egypt.

2. Assisstant Professor, Department of Surgery Oncology, Faculty of Medicine, Alexandria University, Alexandria, Egypt.

3. Department of Surgery Oncology, Faculty of Medicine, Alexandria University, Alexandria, Egypt.

4. Department of Clinical and Chemical Pathology, Faculty of Medicine, Alexandria University, Alexandria, Egypt.

NAME, ADDRESS, E-MAIL ID OF THE CORRESPONDING AUTHOR:

Dr. Amira Ibrahim Fayad,

Department of Clinical and Chemical Pathology, Faculty of Medicine, Alexandria University, Alexandria, Egypt.

E-mail: amira.fayad12@alexmed.edu.eg

Date of Submission: Jul 25, 2019 Date of Peer Review: Aug 21, 2019 Date of Acceptance: Sep 10, 2019 Date of Publishing: Oct 01, 2019 